\title{
Arquivos Vivos da Administração Pública: O Programa de Gestão de Documentos do Estado do Rio de Janeiro (PGD-RJ)
}

\author{
Paulo Knauss de Mendonça \\ Mariana Batista do Nascimento \\ Danilo André Bueno ${ }^{1}$
}

\begin{abstract}
RESUMO
O sentido deste trabalho é caracterizar o processo de construção de uma política pública de arquivos e gestão de documentos no Estado do Rio de Janeiro no contexto contemporâneo distinguido pelo compromisso da democracia e da transparência pública. Assim, apresenta-se o Programa de Gestão de Documentos do Estado do Rio de Janeiro (PGD-RJ), traçando a cronologia do seu desenvolvimento, os elementos constitutivos e característicos da gestão de documentos, a metodologia aplicada e os principais resultados obtidos, com especial atenção à legislação arquivística desde o ponto de vista jurídico da estruturação e implementação do PGD-RJ. Além disso, apresenta as características gerais do Arquivo Público do Estado do Rio de Janeiro (APERJ), sua formação, evolução e marcos legais que legitimam seu papel de autoridade arquivística, com a responsabilidade de definir e implementar a política estadual de arquivos públicos e privados.
\end{abstract}

Palavras-Chave: Arquivo Público; Gestão de Documentos; Legislação Arquivística; Políticas Públicas.

\begin{abstract}
The mean of this paper is to characterize the building process of a archives public policy in the state of Rio de Janeiro in the contemporary context distinguished by the compromise with democracy and public transparency. Thus, the Records Management Program of the State of Rio de Janeiro (PGD-RJ) is presented, tracing the chronology of its development, the constitutive and characteristic elements of records management, the applied methodology and the main results obtained, with special attention to archival legislation from the legal perspective of the structuring and implementation of the PGD-RJ. In addition, it presents the general characteristics of the Public Archive of the State of Rio de Janeiro (APERJ), its formation, evolution and legal frameworks that legitimizes its role as an arquivistic authority

\footnotetext{
${ }^{1}$ Paulo Knauss de Mendonça: Professor do Departamento de História da Universidade Federal Fluminense e Diretor-Geral do Arquivo Público do Estado do Rio de Janeiro. pknauss@ uol.com.br. Mariana Batista do Nascimento: Assessora Técnica do Arquivo Público do Estado do Rio de Janeiro. Danilo André Bueno: Assessor Técnico do Arquivo Público do Estado do Rio de Janeiro.
} 
in the State of Rio de Janeiro, with responsibility for defining and implementing the state policy of public and private archives.

Keywords: Public Archives; Records Management; Archival Legislation; Public Policy.

\section{Tempo presente}

No Brasil contemporâneo, os arquivos se instalaram no processo de redefinição da relação Estado e sociedade. Representam uma das vertentes do processo de reconstrução do Estado no contexto de afirmação da democracia contemporânea brasileira. Sua missão institucional foi renovada especialmente pelo compromisso com a gestão documental, tornando os arquivos equipamentos essenciais para a superação da opacidade do Estado, servindo à transparência pública e ao controle do Estado pela sociedade civil (Jardim, 1995).

A história recente dos arquivos públicos no Brasil tem como marco legal a Constituição Federal de 1988, que, em seu Art. 216 - $\S 2^{\circ}$, define que "Cabe à administração pública, na forma da lei, a gestão da documentação governamental e as providências para franquear sua consulta a quantos dela necessitem”. Este dispositivo ofereceu o aporte necessário para a fundamentação e aprovação da Lei Federal no 8.159 de 8 de janeiro de 1991, mais conhecida como Lei Nacional de Arquivos. É na lei de 1991, em seu Art. $3^{\circ}$, que se define a gestão de documentos como "[...] conjunto de procedimentos e operações técnicas referentes a produção, tramitação, uso, avaliação e arquivamento [de documentos] em fase corrente e intermediária, visando a sua eliminação ou recolhimento para guarda permanente". Mais adiante, a mesma Lei 8.159 em seu Art. $21^{\circ}$ estabelece que "Legislação estadual, do Distrito Federal e municipal definirá os critérios de organização e vinculação dos arquivos estaduais e municipais, bem como a gestão e o acesso aos documentos, observado o disposto na Constituição Federal e nesta Lei”. Nesse sentido, a lei demarcou os arquivos como uma questão da construção do regime federativo no Brasil.

Nos últimos 25 anos, portanto, constata-se um avanço considerável no campo da legislação arquivística no Brasil, com a criação de leis, decretos, resoluções e normas técnicas que regulamentam e orientam as atividades técnicas de produção, acesso, uso, avaliação e preservação de documentos arquivísticos. Por um lado, nos deparamos com a criação de uma base legal arquivística bem sólida nos últimos anos, mas, por outro lado, verificamos que a 
simples existência da legislação não garante sua efetiva aplicação, ou seja, a legislação não pode ser confundida com a ação de execução da mesma.

Concretamente, a legislação arquivística é a base fundamental para o desenvolvimento de políticas públicas no campo dos arquivos, esta última entendida como o conjunto de premissas, decisões e ações produzidas pelo Estado e que devem necessariamente estar inseridas nas agendas governamentais em nome do interesse social contemplando diversos aspectos (administrativo, legal, científico, cultural, tecnológico, etc.) relativos à produção, uso e preservação da informação arquivística de natureza pública ou privada para a posteridade (Jardim, 2003).

A legislação arquivística é o motor das políticas públicas no campo dos arquivos, concretizadas fundamentalmente na elaboração de ações e projetos que envolvem decisões político-administrativas de alcance mais largo. Esta afirmação subjaz à ideia de modernização da administração pública e ultrapassa a questão da renovação dos serviços arquivísticos dos arquivos públicos. Esta é a condição necessária para que qualquer arquivo público seja uma instituição proativa dentro da administração pública, atuando simultaneamente como instrumento da gestão de documentos, referência para o conhecimento e para a memória social, sendo ainda dispositivo decisivo de transparência do Estado, estabelecida por meio de uma política pública bem estruturada.

\section{A construção de políticas públicas}

Para a análise da existência de uma política pública arquivística no âmbito do Estado do Rio de Janeiro, é necessário demarcar conceitualmente o significado de política pública.

Pode-se tomar como pressuposto que o conceito de políticas públicas está diretamente relacionado à própria ideia de Estado sendo compreendido como 'Estado em ação'. A cientista política Celina Souza (2006) ressalta que não há somente uma definição e aponta que as políticas públicas podem ser definidas como um campo dentro dos estudos de política que analisa o governo frente a grandes questões e problemas públicos, ou como um "[...] conjunto de ações de governos que produzam efeitos específicos" (Lynn, 1980 apud Souza, 2006), ou como "[...] a soma das atividades de governos que atuam de forma direta ou por meio de delegação de competência, e que influenciam a vida dos cidadãos (Peters, 1986 apud Souza, 2006). 
José Maria Jardim (2011:200), estudioso das políticas públicas arquivísticas, define política pública como "[...] o conjunto de medidas concretas que formam sua substância e anuncia claramente seus objetivos e metas”. Em síntese, política pública permite que os governos democráticos traduzam seus propósitos e plataformas eleitorais em programas e ações de governo.

Aproximando esses conceitos de políticas públicas com a Arquivística, Jardim (2003) define que as políticas públicas arquivísticas são:

Conjunto de premissas, decisões e ações produzidas pelo Estado e inseridas nas agendas de governos em nome do interesse social - que contemplem os diversos aspectos (administrativos, legal, científico, cultural, tecnológico, etc.) relativos à produção, uso e preservação da informação arquivística de natureza pública e privada.

Para Jardim (2011) é necessário que estas ações se encontrem inseridas necessariamente nas agendas governamentais para que tenham efeitos concretos na sociedade, com a participação de vários atores, e explica ainda que:

A existência de textos legais que regulamentam uma atividade governamental não basta para identificar uma política pública. Por outro lado, nem sempre um conjunto de projetos, leis e ações que caracterizamos como uma política pública é entendido ou enunciado pelo governo. Algumas políticas são mais explícitas ou latentes e outras tomam forma de uma "nãoação" (Jardim, 2011).

De todo modo, segundo o autor, é importante alertar para os conflitos existentes entre o entendimento da elaboração de políticas públicas com a publicação de marcos legais como leis, decretos, resoluções etc., pois um marco legal não garante a existência de uma política pública e tampouco que seja concretizado no plano das ações do Estado. Isso não significa que a legislação não seja considerada importante, pois, de fato, faz parte e é a base para a formulação de políticas públicas. Contudo, somente a legislação não garante a aplicação e tampouco a existência de uma política pública arquivística, conforme explica Jardim (2003):

Políticas públicas arquivísticas existem para responder aos problemas políticos no campo dos arquivos. Isso pressupõe, inicialmente, a necessidade de identificar e analisar os problemas. Reconhecê-los exige um conjunto de conhecimentos simultaneamente técnico-científicos e políticos.

Nesse sentido, o processo de preparação de uma política pública permeia diversas atividades, cada uma com sua devida importância, denominado de policy cycle (ciclo da 
política). Nesse sentido, pode-se tomar como referência que este ciclo é composto de 5 etapas sucessivas e interconectadas para a elaboração de uma política pública: a) a identificação do problema; b) a inclusão [do problema] na agenda de governo; c) a formulação [de estratégias]; d) a implementação; e e) a avaliação da política.

O primeiro momento do ciclo é a identificação do problema pelos atores que deles participam. Para os cientistas políticos Serafim e Dias (2012), é uma etapa considerada subjetiva, pois está condicionada ao "[...] entendimento de valores, de ideias e dos métodos empregados por esses atores para o seu reconhecimento [...]”, e o problema identificado deve ser considerado público.

O segundo momento do ciclo diz respeito à incorporação do problema público identificado na agenda de governo, ou seja, é a priorização dos problemas e assunto de qualquer governo.

O terceiro momento do ciclo consiste nas escolhas estratégicas das opções, dos objetivos e das soluções encontradas para o problema identificado, por meio de um plano de execução.

O quarto momento do ciclo é a implementação da política definida, que consiste na etapa em que serão executadas as ações estratégicas definidas de maneira sistemática na etapa anterior, definida por Serafim e Dias (2012) como "[...] o conjunto de ações que transformam [as estratégias] em resultados concretos e avaliáveis".

O último momento do ciclo é a etapa de avaliação da política no qual se verifica se o problema está sendo solucionado e o grau de solução de acordo com parâmetros de avaliação predefinidos. Os autores analisados apontam que a etapa de avaliação da política "[...] se apresenta como um instrumento técnico que permite o desenvolvimento de processos para a revisão sistemática do grau de solução do problema" (Serafim e Dias, 2012). O resultado dessa etapa pode levar a três situações concretas: melhoria da política implementada; finalização da política existente; e desenvolvimento de uma nova política mais adequada aos problemas identificados.

A leitura dos autores citados aponta que as políticas públicas permitem distinguir entre o que o governo se propõe a fazer e o que concretamente faz; que a política pública abarca vários autores e níveis de decisão, embora seja materializada por meio dos governos, e não necessariamente se restringe a participantes formais, já que a sociedade civil também é importante, visto que possui o maior interesse na resolução da problemática identificada; que 
a política pública é extensa e não se restringe apenas a leis e regras; que a política pública é uma ação intencional, com objetivos que devem ser alcançados mediante um planejamento; que a política pública, embora tenha impactos a curto prazo, deve ser essencialmente uma política de longo prazo; e que a política pública implica processos subsequentes depois de sua identificação, planejamento e tomada de decisão, ou seja, implica implementação, execução, controle e avaliação.

\section{A gestão de documentos na pauta do governo}

A gestão de documentos no Estado do Rio de Janeiro tem como instituição arquivística de referência o Arquivo Público do Estado do Rio de Janeiro (APERJ).

Originalmente, a instituição foi criada por meio do Decreto Estadual nº 2.638 de 25 de agosto de 1931, com a denominação de Arquivo Geral do Estado, subordinado à Secretaria de Interior e Justiça do antigo Estado do Rio de Janeiro, com a competência de receber, classificar e conservar os documentos produzidos pelas distintas secretarias da administração pública estadual. Seu papel principal nessa época era a guarda dos documentos transferidos para sua custódia. Dois anos depois de sua criação teve seu nome substituído para Arquivo Público e Biblioteca Universitária, permanecendo ainda subordinado à Secretaria de Justiça até 1938, quando passou para a Secretaria da Administração do Estado.

Com relação a sua competência, funções e atividades, o Decreto Estadual n ${ }^{\circ} 2.638$ de 1931 não define a necessidade da administração pública de preservar a documentação e os registros que testemunham o desempenho de suas atividades como base para a comprovação de suas realizações, ou que era necessária a conservação dos documentos públicos para que os cidadãos pudessem obter seus direitos, ou ainda que fosse necessária a conservação dos documentos como fontes para a investigação da história.

A análise cuidadosa da legislação evidencia que a administração pública organiza e concebe o Arquivo Público, até a década de 1980, como uma instituição unicamente de guarda de documentos e de investigação para a própria administração pública, sem muitos recursos financeiros, material e de pessoal especializado para sua adequada organização e conservação. Esta situação se modifica com a edição da Lei Federal no 8.159 de 8 de janeiro de 1991, comumente conhecida como Lei Nacional de Arquivos, que ressalta a importância dos Arquivos Públicos como instituições decisivas para a promoção da democracia, centrada 
nos direitos dos cidadãos e como fonte de memória para a reconstrução da história. Esta afirmação está disposta no Art. $1^{\circ}$ da referida Lei, definindo que é dever dos poderes públicos a gestão e proteção especial dos documentos de arquivos, como instrumentos de apoio para a administração, a cultura, ao desenvolvimento científico e como prova e informação, garantindo o direito de acesso pleno aos documentos públicos, exceto os casos previstos em lei.

Em 1994 o APERJ recebeu um novo regimento interno, por meio da Resolução SJU n ${ }^{\circ}$ 478 de 26 de julho de 1994, com o objetivo de adequar-se aos fundamentos dispostos na Lei Federal 8.159, na Constituição Federal e na Constituição do Estado do Rio de Janeiro de 1989, ajustando sua estrutura e seus serviços para garantir a proteção e o acesso aos documentos de arquivo produzidos pela administração. Esta reestruturação ocorreu dois anos após a transferência do Fundo da Polícia Política do Rio de Janeiro ao APERJ, por meio da Lei Estadual nº 2.027 de 29 de julho de 1992, que adicionou ao regimento do APERJ a função de pesquisa probatória, com base no fornecimento de certificados aos cidadãos em busca de seus direitos atingidos pelas medidas repressivas da ditadura militar, ultrapassando a demanda da comunidade acadêmica para a pesquisa da história recente do país.

O regimento produzido em 1994 permaneceu vigente até o ano de 2009, quando por meio da Resolução da Casa Civil no 151 de 9 de julho de 2009 foi alterado, o que consolidou a atual estrutura, competência, funções e atividades do APERJ, destacando a instituição como órgão central da administração dos documentos produzidos pelo Estado, vigente até os dias atuais.

Com relação à sua sede, sua trajetória também é muito problemática. Inicialmente o APERJ foi localizado na cidade de Niterói, dividindo o mesmo prédio com a Biblioteca Estadual de Niterói, de 1930 até 1989.

Em 1989, o APERJ muda de sede, passando a localizar-se em outro edifício na mesma cidade de Niterói, até 1995, quando o Tribunal de Contas do Estado (TCE-RJ) solicitou o edifício ao APERJ para ampliação de suas atividades. Nesse mesmo ano o APERJ foi transferido para a cidade do Rio de Janeiro, para um edifício da Companhia Estadual de Águas e Esgotos (CEDAE).

Em 1998 o APERJ novamente precisou entregar o edifício onde se localizava e, nessa ocasião, instalar-se na Praia de Botafogo no Edifício da Companhia de Transporte sobre Trilhos do Estado do Rio de Janeiro (RIOTRILHOS), onde permanece até os dias atuais, com 
melhores condições que nas sedes anteriores. Embora não sejam condições perfeitas para o armazenamento e tratamento técnico e atendimento ao público, esses fatores são contornados com reformas e adaptações de algumas áreas do edifício.

Todas essas modificações ao longo da existência do APERJ não serviram para fortalecer a instituição arquivística estadual, considerando que o resultado não permitiu constituir um corpo de funcionários próprio e estável, nem garantir uma sede própria e tampouco um grau de autonomia financeira e política que permitisse a realização de projetos e programas de maior alcance social.

Por outro lado, essa história toma novos rumos quando é criado o Conselho Estadual de Arquivos (CONEARQ), por meio do Decreto Estadual no 29.387 de 15 de outubro de 2001, com o objetivo de estabelecer diretrizes para a gestão, preservação e acesso aos documentos produzidos pelo Estado; estudar e propor à Secretaria de Estado da Casa Civil dispositivos legais para o desenvolvimento, aperfeiçoamento e implementação da política pública estadual de arquivos; estimular programas de gestão de documentos, de capacitação técnica de recursos humanos, entre outras ações importantes no âmbito institucional do APERJ. A criação do CONEARQ foi um marco legal essencial para o início da construção de uma política estadual de arquivos e a consolidação do APERJ como instituição arquivística, superando o quadro de falta de respaldo legal e político-administrativo para a sua efetiva atuação frente aos problemas de gestão, organização e acesso aos documentos de arquivos produzidos pelo governo, mudando substancialmente a importância dada aos arquivos e ao APERJ até esse momento.

Outro marco essencial para a consolidação do APERJ e sua missão institucional ocorre quando passa a integrar a estrutura básica da Secretaria de Estado da Casa Civil, em 2007. Nesse mesmo ano, o governo do Estado solicita ao Instituto de Desenvolvimento Gerencial (INDG) a realização de um amplo estudo sobre as condições gerenciais de todas as áreas do governo, com o objetivo de identificar as áreas com maiores problemas no Estado, chegando à conclusão de que uma das áreas mais problemáticas, unindo-se à educação e saúde, era a gestão da informação pública.

Por meio desse estudo realizado pelo INDG, o governo percebeu a necessidade de criar e revisar todos os instrumentos de gestão e de tratamento técnico de documentos de arquivo produzidos pelo Estado. Com esse objetivo, visando à diminuição das massas documentais acumuladas, abandonadas e sem tratamento técnico nos diversos órgãos da 
administração pública estadual, fato que comprometia o acesso aos documentos públicos, o governo aprovou o "Projeto 41 - Modernização Gestão de Documentos Públicos do Estado do Rio de Janeiro e Reestruturação do Arquivo Público". Esse projeto, ao lado de outros 43 projetos e tratados com prioridade por parte do governo do Estado, são projetos estratégicos para a modernização da administração pública do Estado do Rio de Janeiro. Esse instante coloca na pauta de governo o tratamento da questão arquivística no âmbito da administração estadual.

A partir do plano estratégico de desenvolvimento do "Projeto 41", em 2008 a Associação dos Arquivistas Brasileiros (AAB) foi contratada para desenvolver um estudo e uma proposta estratégica para a modernização e reestruturação do APERJ, tanto do ponto de vista jurídico de sua competência, funções e atividades (legislação e marco legal), como no âmbito técnico para a criação de um programa de gestão de documentos (normas, regulamentos, metodologia etc.). Essa consultoria da $\mathrm{AAB}$ teve como produto um relatório detalhado da situação na qual se encontrava o APERJ e entregou o delineamento de uma proposta composta de ações necessárias para conferir a instituição um papel de protagonista e autoridade no cenário arquivístico e na administração pública estadual.

O Projeto 41 tem como objetivos principais: disponibilizar as informações do Estado de forma organizada, acessível e protegida; tornar o APERJ o gestor da documentação estadual com modernas instalações físicas; fortalecer os mecanismos de transparência administrativa e de comunicação; modernizar a gestão de documentos e informações com a integração de sistemas e novas tecnologias. Sob essa inspiração, a análise dos relatórios das consultorias do INDG e da AAB conduziu o governo estadual e o APERJ a criar o Programa de Gestão de Documentos do Estado do Rio de Janeiro (PGD-RJ); o Programa Processo Digital; e o projeto de construção da nova sede do APERJ. Essas três ações decisivas foram inseridas na agenda do governo como partes do Projeto 41, coordenados pela Secretaria de Estado da Casa Civil. ${ }^{2}$

O resultado conduziu a uma revisão geral do marco regulatório dos arquivos no Estado do Rio de Janeiro. Assim, um ano após a criação do Projeto 41 foi sancionada e publicada a Lei Estadual no 5.562 em 20 de outubro de 2009, mais conhecida como Lei Estadual de Arquivos, que dispõe sobre a política estadual de arquivos públicos e privados do Estado do Rio de Janeiro. Seguindo a referência da Lei Nacional de Arquivos, a Lei Estadual define em

\footnotetext{
${ }^{2}$ Há que se lamentar que o projeto da nova sede do APERJ não avançou na mesma medida que as duas outras ações previstas no Projeto 41, do Plano Estratégico de Governo.
} 
seu Art. $1^{\circ}$ que: "É dever dos órgãos e entidades da administração pública estadual a gestão de documentos e a proteção especial de documentos de arquivo, como instrumento de apoio à administração, à cultura, ao desenvolvimento social, educacional e científico, constituindo elementos de prova e informação para o Estado e para o cidadão, para a efetividade dos direitos e garantias individuais e coletivas". 3

A edição da Lei Estadual de Arquivos e o Projeto 41 garantiram uma maior visibilidade estratégica e proativa para o APERJ, com melhores condições financeiras e político-administrativas, ampliação e estabilidade do corpo técnico e de uma estrutura mínima e adequada para a instituição exercer uma política pública arquivística junto à administração pública, de maneira mais autossustentável e coerente com os preceitos de acesso à informação pública produzida pelo Estado.

Concretamente, essas ações apresentadas foram decisivas e estratégicas para a reestruturação administrativa, política e financeira que legitimaram a atuação do APERJ, sendo um dos maiores desafios manter, em longo prazo e com respaldo legal, uma estrutura com corpo técnico próprio, estável e especializado para a criação de um programa de gestão de documentos, garantindo o cumprimento de sua missão e exercer o seu papel de instituição contemporânea com vistas ao atendimento das demandas de acesso à informação governamental por parte do cidadão e da própria administração pública de forma organizada, além de contribuir para a promoção da transparência de Estado.

O que cabe destacar, porém, é a recente inscrição do compromisso com a gestão de documentos na agenda de governo e que marca mais um passo no processo de construção de uma política arquivística estadual.

\section{Dimensões da produção documental}

Os dados sobre a produção documental do Estado do Rio ainda não foram sistematizados de modo aprofundado, carecendo de uma análise consistente de série histórica. Somente no ano de 2013 o sistema de protocolo estadual foi unificado e generalizado fazendo

\footnotetext{
${ }^{3} \mathrm{O}$ acesso aos documentos produzidos pelo Estado foi garantido com a publicação do Decreto Estadual $\mathrm{n}^{\circ}$ 43.597 de 16 de maio de 2012, que regulamenta o procedimento de acesso às informações previsto nos artigos $5^{\circ}$, XXXII, e 216, § 2º da Constituição Federal da República de 1988, e na Lei Federal no 12.527 de 18 de novembro de 2011, conhecida como Lei de Acesso à Informação (LAI).
} 
uso de uma base operacional informatizada que permitirá aumentar o conhecimento sobre a produção documental estadual.

Contudo, graças ao levantamento realizado pelo INDG em 2007, é possível reunir alguns dados que permitem dimensionar a questão da produção documental na administração pública estadual. No período de novembro/2006 a outubro/2007 foram adicionados ao Sistema Integrado de Protocolo Eletrônico estadual aproximadamente 869.000 novos processos que representaram mais de 3 milhões de tramitações durante este período, conforme gráfico que se segue.

\section{Gráfico 1. Produção documental na administração pública estadual}

(nov.2006-out.2007)

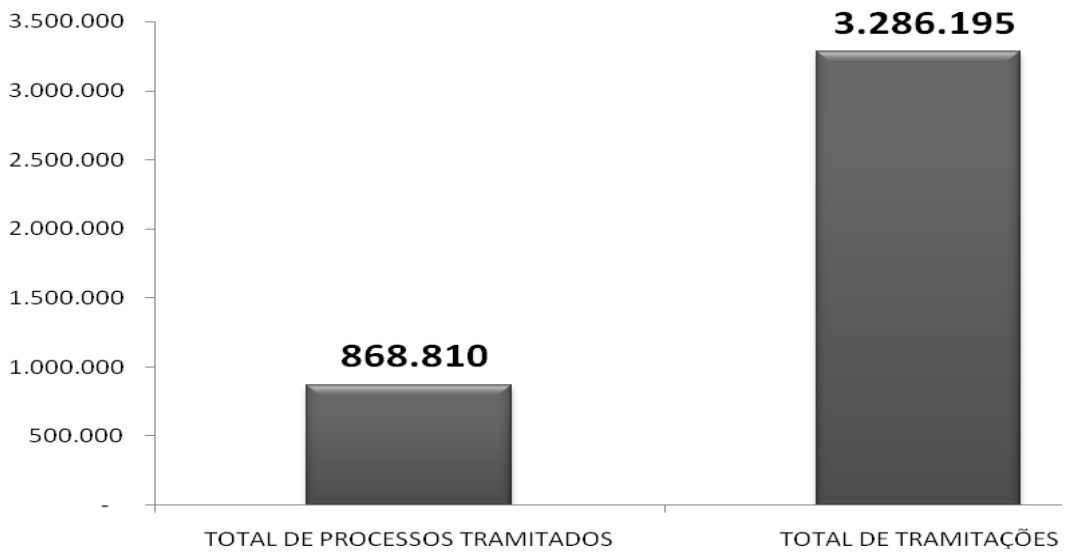

Fonte: INDG.

O dado precisa ser relativizado, considerando que na altura o sistema de protocolo eletrônico ainda não havia sido generalizado na administração estadual, o que significa dizer que o resultado constatado fornece uma medida nada precisa da dimensão da produção documental, permitindo assegurar, no entanto, que certamente é maior do que o número indicado. De todo modo, com o dado apontado, pode-se ainda dizer que em média a administração pública estadual produzia naquela altura algo próximo de 72.400 processos por mês.

Ao lado disso, é possível indicar ainda os órgãos que, na época do levantamento de dados, eram os maiores produtores de processos autuados. 


\section{Gráfico 2. Processos autuados por órgãos estaduais}

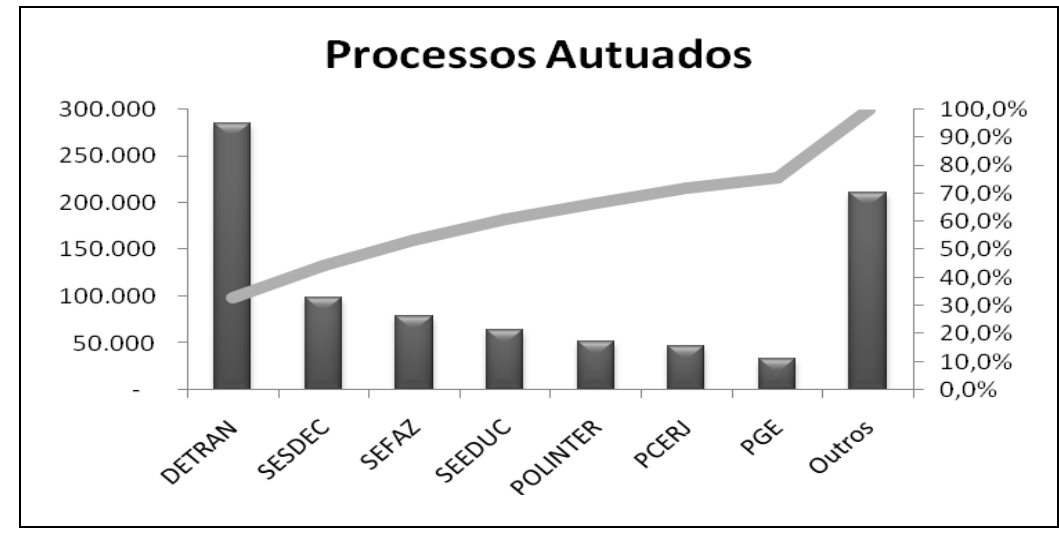

Fonte: INDG.

Diante dos dados fornecidos, constata-se que o Departamento de Trânsito do Estado do Rio de Janeiro (DETRAN-RJ) é isoladamente o órgão que mais autuava processos no âmbito do Poder Executivo estadual, com cerca de 33\%, seguido pela Secretaria de Saúde e Defesa Civil com 11\%, a Secretaria de Fazenda com 9\%, a Secretaria de Estado de Educação (SEEDUC) com 7\%, a Delegacia de Capturas e Polícia Interestadual (Polinter) com 6\%, a Polícia Civil do Rio de Janeiro (PC-RJ) com 5\% e a Procuradoria Geral do Estado do Rio de Janeiro (PGE) com 4\%. O conjunto representado por estes órgãos corresponde a algo próximo de $76 \%$ do total dos processos autuados entre 2006 e 2007.

Ora, ainda que estes dados possam apresentar variações numa série histórica, é possível considerar que o seu resultado geral permite apontar os órgãos que são estratégicos para o controle da produção documental da administração pública estadual levando em conta o volume de autuação de processos. Não há como deixar de evidenciar que se colocam em posição de destaque para o desenvolvimento de qualquer ação abrangente no campo da gestão de documentos estadual.

Em cada um dos órgãos é possível também identificar o quadro de processos autuados identificando os que mais mobilizam o trabalho do órgão. O melhor exemplo é o do DETRAN-RJ como maior produtor isolado de processos administrativos, dos quais os processos de recursos de multa e isenção de taxas se destacam. 


\section{Gráfico 3. Processos administrativos do DETRAN-RJ}

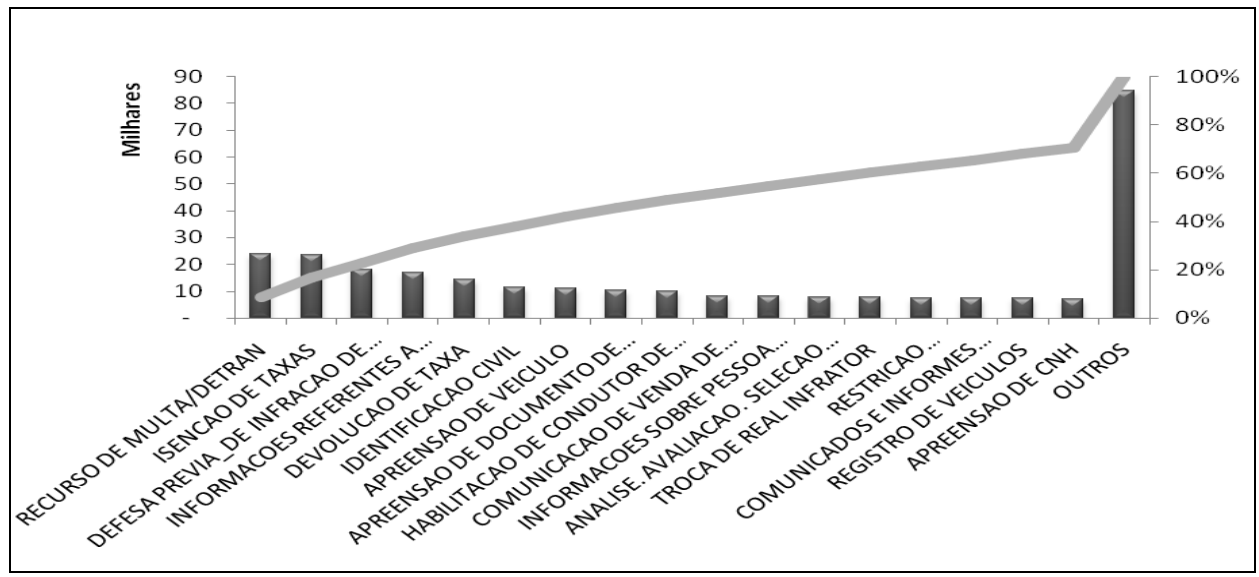

Fonte: INDG.

O caso do DETRAN-RJ também indica a diversidade de processos produzidos pelo órgão. Há outros casos de órgãos grandes produtores de processos, mas cuja diversidade é bem menor, como no exemplo da PGE-RJ, em que um processo de certidão negativa da dívida ativa predomina acentuadamente no quadro geral.

\section{Gráfico 4. Processos administrativos da PGE-RJ}

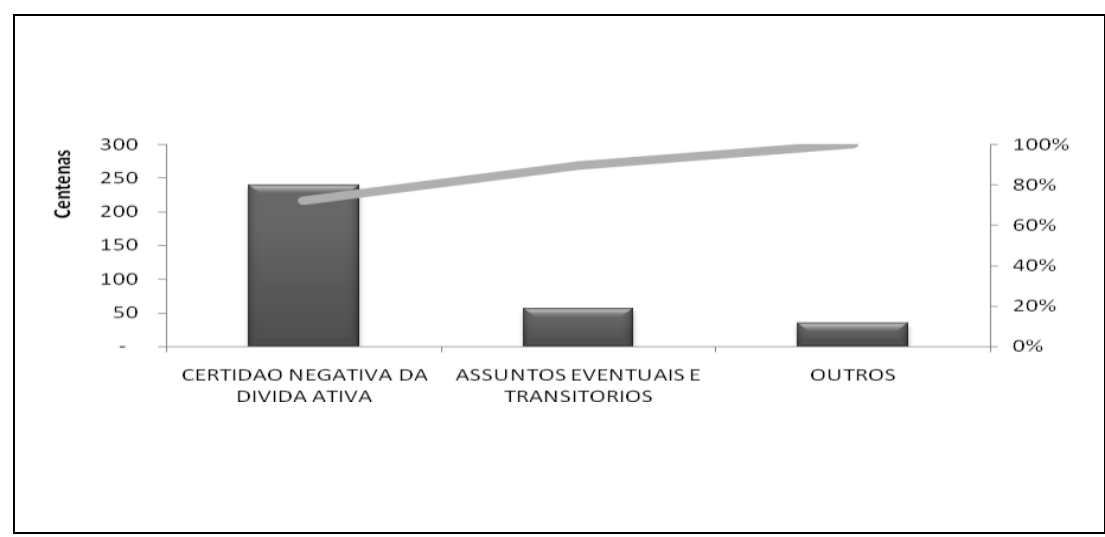

Fonte: INDG.

Os dados gerais apresentados permitem interrogar também os custos do sistema vigente de produção de documentos a partir do exemplo das guias de remessa. 
Tabela 1. Estimativa de custos da produção de guias de remessa

\begin{tabular}{|ll|}
\hline ITEM & MEDIDA \\
\hline Número Processos / Ano & 869.000 \\
\hline Trâmite / Processo & 3,78 \\
\hline Número de Vias de Guia de Remessa / Trâmite & 3 \\
\hline Número de Folhas / Via de Guia de Remessa & 1,5 \\
\hline Custo de Folha (R\$) (estimativa) & 0,40 \\
\hline Custo total (R\$) (estimativa) & $\mathrm{R} \$ 2.627 .856,00$ \\
\hline
\end{tabular}

Fonte: PDG-RJ.

Levando-se em conta que cada processo tramita em média 3,78 vezes e cada tramitação produz 3 guias de remessa, necessitando o consumo de uma folha e meia de papel, ao final a quantidade de folhas de papel por guia de remessa a cada processo totalizaria 7,56 folhas consumidas. Por consequência, tomando-se o total de processos/ano 869.000 multiplicado por 7,56 correspondente ao número de folhas consumidas em média pela tramitação dos processos, a um custo de $\mathrm{R} \$ 0,40$ (quarenta centavos) por folha, chegaríamos a um total de $\mathrm{R}$ \$ 2.627.856,00 (dois milhões, seiscentos e vinte e sete mil e oitocentos e cinquenta e seis reais)/ano. Sem contar variações financeiras e de tendência de aumento da produção de processos, pode-se estimar que, ao fim de 10 anos, apenas o custeio das guias de remessa em papel seria mais de 26 milhões de reais.

No caso do Estado do Rio de Janeiro, a generalização obrigatória do uso do Sistema Eletrônico Integrado de Protocolo e produtor de guias de remessa eletrônicas na administração pública estadual, no ano de 2013, permite antever um horizonte de economia no custeio de sua produção. Há que se considerar que esta medida da guia de remessa do ponto de vista quantitativo é muito pouco significativa no conjunto da produção documental com proporções muito maiores. A falta de capacidade do Estado de quantificar a produção documental evidencia um certo descontrole sob o seu sentido estratégico. Os dados levantados, porém, possibilitam avaliar a proporção do custo do sistema de comunicação administrativa e de produção de documentos em papel e a importância de se fazer um acompanhamento aprofundado da ordem vigente e legitimar investimentos. Certo é que a transformação do quadro atual dificilmente pode ser contornada sem investimentos em normatização, padronização e inovação tecnológica.

Em resumo, para além dos sentidos políticos gerais que legitimam a valorização de uma política arquivística que emana do compromisso com a democracia e a transparência 
pública, trata-se de enfatizar que a gestão de documentos se impõe como uma dimensão fundamental da vida da administração pública e que merece uma atenção especial no sentido de aumentar a eficiência do Estado.

\section{O Programa de Gestão de Documentos do Estado o Rio de Janeiro (PGD-RJ): fundamentos e resultados}

Para fazer face ao quadro vigente de produção documental na administração pública estadual, foi criado o Programa de Gestão de Documentos do Estado do Rio de Janeiro, mais conhecido como PGD-RJ, determinado pelo Decreto Estadual no 42.002 de 21 de agosto de 2009, que dispõe sobre a avaliação e destinação de documentos produzidos e recebidos pela administração pública do Estado do Rio de Janeiro. Sua criação foi reforçada pela aprovação da Lei Estadual nº 5.562 de 20 de outubro de 2009.

No Decreto Estadual n 42.002, o governo determina a revisão e o desenvolvimento de novos Planos de Classificação de Documentos e de Tabela de Temporalidade de Documentos das atividades-meio e das atividades-fim da administração pública estadual. A coordenação do trabalho de desenvolvimento e revisão desses instrumentos foi atribuída ao APERJ e à Secretaria de Estado da Casa Civil, contando com o apoio da Universidade Federal Fluminense por meio de convênio para engajar estagiários e consultoria no campo metodológico e da pesquisa.

O PGD-RJ tem como objetivos principais: a disponibilização das informações produzidas ou recebidas pela administração pública estadual de forma organizada, acessível e protegida; a atuação do Arquivo Público do Estado do Rio de Janeiro como gestor da documentação estadual; o fortalecimento de mecanismos de transparência administrativa e de comunicação; a modernização da gestão de documentos e informações; e a integração dos sistemas e tecnologias (Manual..., 2012). ${ }^{4}$

O PGD-RJ se estrutura por meio do trabalho das Comissões de Gestão de Documentos (CGDs) existentes em cada órgão e entidade da administração pública estadual, coordenado por um comitê gestor que tem como presidente o diretor-geral do APERJ. Nesse sentido, o APERJ lidera o Sistema Estadual de Arquivos (SIARQ-RJ), regulamentado pelo Decreto

\footnotetext{
${ }^{4}$ Manual de Gestão de Documentos. Disponível em: <http://www.aperj.rj.gov.br/doc/manual\%20de\%20gestao.pdf〉.
} 
Estadual $\mathrm{n}^{\circ} 43.871$ de 08 de outubro de 2012. As competências do comitê gestor são disseminar, normalizar e estimular as atividades de gestão de documentos (produção, classificação, avaliação, tramitação, uso e arquivamento dos documentos, bem como o acesso aos mesmos) no âmbito dos órgãos e entidades da administração pública do Poder Executivo do Estado do Rio de Janeiro, preservando a memória institucional e social do Estado.

Por meio das CGDs, o PGD-RJ desenvolve todo o trabalho de elaboração e revisão dos Planos de Classificação de Documentos e Tabelas de Temporalidade Documental das atividades-fim do Poder Executivo do Estado do Rio de Janeiro, instrumentos básicos do PGD-RJ.

As CGDs tendem a ser formadas por um membro representante de cada área-fim do órgão ou entidade, um especialista em documentação e um especialista em protocolo dos órgãos e entidades da administração pública direta e indireta do Estado, com a indicação de um membro presidente da CGD, publicada posteriormente por meio de portaria com a sequência de suplência de seus membros.

Atualmente existem 115 (cento e quinze) CGDs nomeadas, que estão divididas entre 25 (vinte e cinco) secretarias de Estado, 14 (quatorze) fundações, 5 (cinco) empresas públicas, 9 (nove) sociedades de economia mista, 23 (vinte e três) autarquias, 48 (quarenta e oito) conselhos, 29 (vinte e nove) fundos, 8 (oito) empresas em liquidação e 9 (nove) institutos.

Para a implementação do PGD-RJ, é empregada a metodologia de Identificação Arquivística, fundamentada nos estudos de Diplomática e de Tipologia Documental, por meio do Sistema de Identificação de Tipologia Documental (SITD) (Manual..., 2012).

De acordo com o Dicionário Brasileiro de Terminologia Arquivística (2005), a Identificação Arquivística é definida como “[...] processo de reconhecimento, sistematização e registro de informações sobre os arquivos, com o objetivo de alcançar seu controle físico e intelectual". A identificação de tipologias documentais se fundamenta nos princípios teóricos e metodológicos da Diplomática Contemporânea, que é definida como “[...] os estudos das formas e dos processos de formação dos documentos de arquivo, entendidos como documentos criados ou recebidos por uma pessoa física ou jurídica no exercício de suas atividades práticas" (Bellotto, 2002).

A Identificação Arquivística é uma etapa imprescindível que se caracteriza como um estudo analítico do órgão produtor e dos documentos produzidos. Consiste no levantamento de dados sobre o órgão produtor, seu elemento orgânico (estrutura organizacional) e seu 
elemento funcional (competências, funções e atividades) que determinarão as características que apresentam as tipologias documentais produzidas ou recebidas no âmbito de sua estrutura organizacional e provenientes de sua competência, funções e atividades. O resultado prático dessa atividade de investigação obterá a identificação do contexto de produção e das características específicas de cada tipologia documental identificada, atividade que subsidia o planejamento da produção, tramitação, classificação, avaliação, acesso e uso dos documentos de arquivo, que consiste da análise crítica sobre sua gênese.

Essas informações coletadas por meio da metodologia de Identificação Arquivística são a base para a elaboração dos Planos de Classificação de Documentos e das Tabelas de Temporalidade de Documentos, que consiste em representar fielmente os documentos por meio de seu contexto de produção, distinguindo os mesmos através dos seus órgãos de produção, competência, funções e atividades, que se articulam formando o fundo de documentos dos órgãos e em estabelecer seus prazos de guarda e destinação.

Por meio do Sistema de Identificação de Tipologias Documentais (SITD), o PGD-RJ desenvolve suas funções arquivísticas, cujo resultado prático favorece o controle e elaboração dos instrumentos de gestão de documentos, o Plano de Classificação de Documentos e a Tabela de Temporalidade de Documentos. O SITD é um banco de dados informatizado desenvolvido especialmente para o PGD-RJ, com apoio do PRODERJ, e se caracteriza como um instrumento técnico de aplicação da metodologia de Identificação Arquivística. A inserção de dados no sistema SITD é de responsabilidade das CGDs de cada órgão produtor dos documentos, que recebem treinamento e orientação teórica e metodológica quanto à execução e aplicação da metodologia por parte do APERJ.

O SITD é dividido em dois módulos: Módulo 1 - Identificação das Atribuições dos Órgãos Produtores e Módulo 2 - Identificação de Tipologias Documentais.

Os dados inseridos no Módulo 1 do SITD são coletados a partir da análise das normas jurídicas que dispõe sobre as estruturas e funcionamento dos órgãos e entidades da administração pública do Poder Executivo do Estado do Rio de Janeiro (regulamentos, estatutos, leis, decretos, regimento interno etc.), cujo resultado será estabelecer um quadro de identificação de atribuições dos órgãos, com os seguintes elementos: competências; funções; atividades; e áreas administrativas do órgão produtor estudado.

Depois de definidas as atribuições legais de um determinado órgão, inicia-se a alimentação do Módulo 2 - Identificação das Tipologias Documentais, onde serão realizadas 
as associações das atribuições identificadas no Módulo 1 com os documentos identificados nesse referido órgão em análise. O Módulo 2 tem como finalidade o registro de todos os requisitos dos documentos produzidos ou recebidos por um órgão, e possui os seguintes elementos de identificação: nome atual; objetivo de produção; conteúdo do documento; fundamentos legais; espécie; tipologia documental; restrição de acesso; suporte; tramitação; prazos de guarda nos arquivos correntes, intermediários e destinação final.

Todos os dados inseridos no SITD são analisados pela Equipe da Divisão de Gestão de Documentos do APERJ, que por meio de relatórios gerados pelo sistema operacional cria os Planos de Classificação de Documentos e Tabelas de Temporalidade de Documentos das atividades-meio e fim dos diversos órgãos e entidades da administração pública do Poder Executivo do Estado do Rio de Janeiro.

Os dados dos Planos de Classificação de Documentos e das Tabelas de Temporalidade Documental produzidos pelo PGD-RJ são estrategicamente desenvolvidos para integrar o Projeto Processo Digital, permitindo integrar a gestão de documentos com a produção de documentos eletrônicos da administração pública do Poder Executivo do Estado do Rio de Janeiro. Esta metodologia se mostra muito eficaz, pois permite classificar o documento em sua origem, integrando os procedimentos de gestão durante todo o ciclo de vida dos documentos, desde sua produção até a sua destinação final. Além disso, é importante ressaltar que com a aplicação da metodologia apresentada o documento de arquivo já vem classificado com o grau de sigilo para cada documento de acordo com o que determina a Lei de Acesso à Informação (Lei Federal $n^{\circ} 12.527$ de 18 de novembro de 2011), bem como as formas de controle e acesso desde sua produção, tornando o SITD um instrumento fundamental para a gestão de acesso à informação, por meio da gestão de documentos.

Por fim, a publicidade dessas informações no site institucional do APERJ permite a transparência ativa e contínua das informações produzidas pela administração pública do Poder Executivo do Estado do Rio de Janeiro, fornecendo os dados sobre a estrutura completa dos órgãos produtores, os tipos de documentos produzidos e as condições para o seu acesso. Esta é a importância do trabalho desenvolvido pelo APERJ com o PGD-RJ, ou seja, tornar públicas as informações produzidas pelo Estado, por meio da transparência administrativa dos governos como prestação de contas para com os cidadãos. 
Os resultados obtidos com o PGD-RJ ao longo dos cinco anos de trabalho foram cursos e seminários de apoio às atividades do PGD-RJ, além da produção de instrumentos essenciais de gestão de documentos.

Assim, em 2010 foi oferecido a toda a administração pública estadual o curso "Fundamentos Teóricos para a Elaboração de Instrumentos de Gestão de Documentos", destinado aos profissionais das Comissões de Gestão de Documentos (CGDs) do Estado para a capacitação e orientação teórica e técnica dos membros para a aplicação da metodologia de Identificação Arquivística com vistas à coleta de informações necessárias para a elaboração dos Planos de Classificação de Documentos e Tabelas de Temporalidade Documental dos diversos órgãos e entidades do Estado do Rio de Janeiro (curso contínuo desde 2010). Ao lado disso, ainda no ano de 2010, foram realizados uma oficina especializada - "Jornada de Gestão de Documentos”, com o professor Joaquim Llansó Sanjuan, diretor do Archivo General de la Universidad de Navarro, Espanha - e o "Seminário de Estudos Arquivísticos - A Gestão Documental e o Contexto da Administração Pública Estadual no Brasil”, que tinha como objetivo discutir os fundamentos, modelos, experiências, metodologias e resultados obtidos com a gestão de documentos na administração pública brasileira, com o intercâmbio de experiências tanto a nível nacional como internacional.

No que se refere aos instrumentos de gestão de documentos é possível indicar a publicação, em 2012, do "Plano de Classificação e Tabela de Temporalidade de Documentos das Atividades-meio do Estado do Rio de Janeiro", aprovada e publicada, incluindo um total de 883 tipos documentais identificados. No momento, já se prepara uma nova edição revista e ampliada que deve ser lançada no ano de 2014. Em 2012 foi lançada ainda a primeira edição do Manual de Gestão de Protocolo e, a partir de sua aplicação e das sessões de treinamento para sua aplicação, foi produzida nova edição revisada e publicada em 2013. Sua publicação foi acompanhada ainda de cartilhas de gestão de documentos, acesso à informação e protocolo. Além disso, entre 2012 e 2013 foram publicados 8 Planos de Classificação de Documentos e Tabelas de Temporalidade de Documentos das Atividades-fim de órgãos estaduais aprovados e publicados, incluindo mais de 300 tipos documentais identificados. ${ }^{5}$

5 Os Planos de Classificação de Documentos e respectivas Tabelas de Temporalidade de Documentos de Atividades-fim já publicados se referem aos seguintes órgãos: APERJ, LOTERJ, FAPERJ, FIA, PROCON, CODERTE, RIOPREVIDENCIA, SEEDUC. Encontram-se em fase de publicação: INEA, PESAGRO, DEGASE, DPPE e Casa Civil. 
Portanto, no âmbito do PGD-RJ têm sido produzidos os instrumentos técnicos típicos da gestão documental (Planos de Classificação de Documentos e Tabelas de Temporalidade de Documentos) além de manuais que buscam padronizar procedimentos gerais, criando um ambiente corporativo comum. Neste caso, o programa de treinamento tem um papel importante ao reunir regularmente os servidores do mesmo órgão ou de vários órgãos estabelecendo uma linguagem compartilhada. A produção dos Planos de Classificação de Documentos e Tabelas de Temporalidade de Documentos persegue o objetivo de abarcar principalmente os maiores órgãos produtores de documentos. Os mais destacados DETRAN-RJ, Polícia Civil, PGE - se encontram em fase de desenvolvimento com previsão de publicação no ano de 2014. A estes produtos, soma-se ainda a nova edição revisada do Manual de Redação Oficial de Documentos do Estado do Rio de Janeiro, com publicação prevista para o início de 2014, representando mais um instrumento essencial do Programa de Gestão de Documentos do Estado do Rio de Janeiro.

De modo geral, portanto, é possível indicar que, a partir da difusão de uma metodologia de trabalho fundamentada em conceitos próprios do pensamento arquivístico, o PGD-RJ se desdobra num amplo programa de capacitação de servidores em serviço para operar sistema de coleta de dados e elaborar manuais e instrumentos técnicos próprios para a gestão documental em seus lugares de trabalho. Trata-se de uma ação de ampla mobilização de inúmeros servidores em cada repartição administrativa onde se implanta e se desenvolve.

\section{Transparência ativa}

O objetivo mais importante do Programa de Gestão de Documentos do Estado do Rio de Janeiro (PGD-RJ) é publicizar o quadro geral da produção de documentos no âmbito da administração pública estadual. O seu resultado consiste essencialmente na publicidade das funções e atividades dos órgãos e entidades estaduais que contextualizam e legitimam a sua produção documental expressa na identificação e listagem de tipos documentais. O resultado fornece não apenas um quadro geral da administração pública, mas serve especialmente para o cidadão conhecer que tipo de informação é produzida na administração pública, reconhecendo as condições de sua produção. Fundamentalmente, trata-se de um instrumento para informar ao cidadão sobre o Estado e suas ações, orientando o acesso à informação, além de constituir um recurso ímpar para o controle do Estado. A produção e disponibilização dos 
instrumentos de gestão de documentos pode ser um instrumento vivo da transparência ativa em que o Estado se organiza para oferecer dados sobre seu funcionamento ao cidadão. $\mathrm{O}$ PGD-RJ se singulariza por definir gestão de documentos com um instrumento importante do acesso à informação.

$\mathrm{Na}$ atualidade do Estado do Rio de Janeiro, pode-se apontar o desenvolvimento de um processo de construção de política pública arquivística. Não há dúvida de que a gestão de documentos se impõe na atualidade à relação do Estado com a sociedade, seja pela identificação dos problemas envolvidos, seja pelo seu reconhecimento na agenda de governo. Este processo tem sido organizado pela formulação de estratégias, que emanam de um marco regulatório renovado, e pela implementação do PGD-RJ, que traduz uma ação estruturada para alcançar os objetivos traçados. Sua integração com a implantação do sistema de produção de documentos digitais, por meio do Projeto Processo Digital desenvolvido pela Secretaria de Estado da Casa Civil no quadro do Sistema Estadual de Arquivos, demonstra o alcance e a abrangência das iniciativas que vêm sendo empreendidas na atualidade estadual. Há claramente um processo de construção de política pública arquivística em desenvolvimento. Completa esse quadro a necessidade de avançar na avaliação dos resultados e do desenvolvimento dos projetos e ações implementadas e aprofundar o conhecimento do universo da produção documental da administração pública.

O fato é que o APERJ e o PGD-RJ devem cumprir, sobretudo, o papel de dar visibilidade ao mundo dos arquivos e à produção documental na administração pública do Estado do Rio de Janeiro, superando a invisibilidade e o estigma do arquivo morto que só pode existir onde o Estado seja marcado pela opacidade e desprezo pela coisa pública. Diante da atualidade do controle social do Estado e do compromisso com a transparência pública, os arquivos são cada vez mais necessários e vivos como instrumentos da democracia. Daí a importância de se afirmar uma política pública de Estado que não seja suscetível às mudanças de governo e garanta o lugar dos arquivos para a valorização do serviço público e o fortalecimento da ordem democrática. 


\section{Referências Bibliográficas e Legislação}

ARQUIVO NACIONAL (Brasil). Dicionário brasileiro de terminologia arquivística. Rio de Janeiro: Arquivo Nacional, 2005. 232p. (Publicações Técnicas; nº 51).

BRASIL. Constituição da República Federativa do Brasil de 1988. Art. $5^{\circ}$ - Incisos: X, XIV, XXXIII, XXXIV, LX, LXXII, LXXIII e Art. 216º,$\S 2$, art. 23.

BRASIL. Lei $n^{\circ} 8.159$, de 08 de janeiro de 1991 - Dispõe sobre a política nacional de arquivos públicos e privados e dá outras providências.

BELLOTO, H. L. Como fazer análise diplomática e análise diplomática e análise tipológica de documento de arquivo. São Paulo: Arquivo do Estado, Imprensa Oficial, 2002. 120p. (Projeto como Fazer, 8).

JARDIM, José Maria. Transparência e opacidade do Estado no Brasil; usos e desusos da informação governamental. Niterói: EDUFF, 1995.

. O Inferno das boas intenções: Legislação e políticas arquivísticas. In: MATTAR, Eliane (org.). Acesso à informação e política de arquivos. Rio de Janeiro: Arquivo Nacional, 2003.

. Políticas Públicas de informação: a (não) construção da política nacional de arquivos públicos e privados (1994-2006). In: LARA, Marilda Lopes Ginez de; SMIT, Johanna Wilhelmina (Orgs.). Temas de Pesquisa em Ciência da Informação no Brasil. São Paulo: Escola de Comunicação e Artes/SP, 2010. pp. 201-216.

- Obstáculos à construção de políticas nacionais de arquivos no Brasil e na Espanha: uma abordagem teórico-metodológica de análise comparada. Liinc em Revista, v. 7, pp. 197 213, 2011.

MANUAL DE GESTÃO DE DOCUMENTOS. Rio de Janeiro: Arquivo Público do Estado Rio de Janeiro 2012.

RIO DE JANEIRO. Lei $N^{o}$ 5427, de 01 de abril de 2009. Estabelece normas sobre atos e processos administrativos no âmbito do Estado do rio de janeiro e dá outras providências.

RIO DE JANEIRO. Lei $n^{o} 5.562$, de 20 de outubro de 2009. Dispõe sobre a política de arquivos públicos e privados do Estado do Rio de Janeiro e dá outras providências. 
RIO DE JANEIRO. Decreto $n^{\circ} 42.002$, de 24 de agosto de 2009. Dispõe sobre avaliação e destinação de documentos produzidos e recebidos pela administração pública estadual e dá outras providências.

RIO DE JANEIRO. Decreto $n^{\circ} 42.352$ de 15 de março de 2010. Regulamenta a lei estadual $\mathrm{n}^{\mathrm{o}} 5.427$ de 01 de abril de 2009, no que dispõe sobre a informatização de documentos e processos administrativos na administração pública estadual e dá outras providências.

RIO DE JANEIRO. Decreto $n^{\circ} 43.992$ de 14 de dezembro de 2012. Aprova o plano de classificação de documentos e a tabela de temporalidade das atividades-meio do Poder Executivo do Estado do Rio de Janeiro.

RIO DE JANEIRO. Decreto $n^{\circ} 43.897$ de 16 de outubro de 2012. Aprova o manual de gestão de protocolo e institui a numeração única de protocolo no âmbito do Poder Executivo estadual e dá outras providências.

RIO DE JANEIRO. Decreto $n^{\circ} 43.871$ de 08 de outubro de 2012. Dispõe sobre a criação do Sistema de Arquivos do Estado do Rio de Janeiro - SIARQ-RJ e dá outras providências.

RIO DE JANEIRO. Decreto $N^{o} 44.012$ de 02 de janeiro de 2013. Aprova o manual de gestão de documentos e institui a padronização do procedimento para atendimento à lei de acesso a informação e dá outras providências.

SERAFIM, Milena Pavan; DIAS, Rafael de Brito. Análise de política: uma revisão de literatura. Cadernos Gestão Social, vol. 3, n. 1, pp. 121-134, Salvador, jan./jun. 2012.

SOUZA, C. Políticas públicas: uma revisão da literatura. Sociologias, ano 8, n. 16, pp. 20-45, Porto Alegre, 2006. 